\title{
IDENTIDADE, DOCÊNCIA E FORMAÇÃO DE PROFESSORAS QUE ATUAM EM CRECHES: UM DIÁLOGO COM A PESQUISA
}

\author{
Núbia Schaper Santos ${ }^{1}$, Víviam Carvalho de Araújo ${ }^{2}$, Wagner Silveira Rezende ${ }^{3}$ \\ ${ }^{1}$ Doutora em Educação, Docente do Programa de Pós-Graduação em Educação - Universidade Federal de Juiz de Fora \\ - UFJF. \\ ${ }^{2}$ Doutoranda em Educação no Programa de Pós-Graduação em Educação - Universidade Federal de Juiz de Fora - \\ UFJF. E-mail: viviamc@gmail.com \\ ${ }^{3}$ Doutor em Ciências Sociais pela Universidade Federal de Juiz de Fora - UFJF e Doutorando em Educação no Programa \\ de Pós-Graduação em Educação - Universidade Federal de Juiz de Fora - UFJF.
}

\section{RESUMO}

Este artigo apresenta dados da pesquisa intitulada "Sentidos e significados sobre a formação do(a) professor(a) das creches conveniadas do município de Juiz de Fora/MG", que foi desenvolvida pelo Grupo de Pesquisa Linguagens, Infâncias, Cultura e Desenvolvimento Humano (GP LICEDH) da Faculdade de Educação ( FACED) da Universidade Federal de Juiz de Fora/MG (UFJF). A referida investigação teve por objetivo construir o perfil das professoras que atuam em 26 creches conveniadas do município, buscando compreender quais são os saberes/fazeres docentes necessários para atuação com bebês e crianças na faixa etária de 0 a 3 anos de idade. A primeira etapa da pesquisa, que será aqui discutida, utilizou uma abordagem quantitativa, que permitiu construir um questionário de escala de resposta psicométrica tipo Likert, que foi respondido por 248 professoras. Em uma segunda etapa, utilizou-se uma abordagem qualitativa de pesquisa, possibilitando compreender os sentidos e significados que foram construídos entre as participantes. Os dados produzidos na pesquisa demonstram uma falta de identidade das profissionais que trabalham nas creches com a docência na Educação Infantil. A ausência de investimento dos gestores municipais na garantia de uma carreira específica, com salários dignos e com tempo destinado à formação para essas profissionais também foram questões impactantes reveladas pela investigação. $O$ estudo aponta para a necessidade de uma articulação orgânica entre as políticas de Educação em nosso país, sendo fundamental que o poder público municipal assuma, de fato, as creches como primeira etapa da Educação Básica.

Palavras-chave: Educação Infantil. Creche. Formação de professores. Condição de trabalho docente.

\section{IDENTITY, TEACHING, AND DEVELOPMENT OF TEACHERS WHO WORK IN DAYCARE: A DIALOGUE WITH THE RESEARCH}

\section{ABSTRACT}

This article presents data from the research entitled "Sense and meanings on public daycare teacher training in the city of Juiz de Fora / MG", which was developed by the Research Group on Languages, Childhood, Culture and Human Development (GP LICEDH) from the Faculty of Education (FACED) at the Federal University of Juiz de Fora / MG - UFJF. The referred investigation aimed at building the profile of the teachers who work in 26 municipal daycare centers, seeking to understand what are the necessary teaching knowledge and tasks to work with babies and children in the 0-3 age group. The first stage of the research, which we will discuss here, used a quantitative approach, that allowed the construction of a Likert-type psychometric response scale questionnaire, which was answered by 248 teachers. In a second stage, a qualitative research approach was used, making it possible to understand the sense and meanings forged among the participants. The data produced in the research demonstrate a lack of identification of the professionals who work in daycare centers with teaching in Early Childhood Education. The lack of investment from the city management in views of guaranteeing a specific career, with decent wages and with time destined for the development of these professionals, were also impactful issues revealed by the investigation. The study points to the need of an organic articulation between the Education policies in our country, and it is paramount for the municipal public power to, indeed, acknowledge daycare as the first stage of Basic Education.

Keywords: Early Childhood Education. Daycare. Teacher training. Teachers working conditions. 


\section{INTRODUÇÃO}

Este artigo tem por objetivo apresentar a pesquisa intitulada "Sentidos e significados sobre a formação do(a) professor(a) ${ }^{1}$ das creches conveniadas do município de Juiz de Fora/MG", que foi desenvolvida pelo Grupo de Pesquisa Linguagens, Infâncias, Cultura e Desenvolvimento Humano (GP LICEDH) da Faculdade de Educação (FACED) da Universidade Federal de Juiz de Fora (UFJF). O foco da investigação centrou-se na discussão sobre a formação e condições de trabalho da(s) professora(s) que atuam em creches. Partiu-se da premissa que a formação de professores e as pesquisas, em suas diferentes modalidades, precisam dialogar com o universo educacional brasileiro, marcado por suas complexidades e contradições, em um movimento dialético, no qual todos os envolvidos contribuam mutuamente para as discussões e para os rumos das políticas e ações voltadas para a educação.

Consideramos a necessidade de problematizar acerca dos saberes/fazeres necessários à constituição docente para lidar com bebês e crianças pequenas em contextos coletivos de educação. As pesquisas que elegem os saberes/fazeres das professoras da creche são em número reduzido, quando analisamos a produção acadêmica no campo da Educação. Partimos do princípio de que as perguntas sobre quem são as profissionais que atuam nessas creches, quais são suas condições de trabalho, como refletem sobre a sua prática e sob quais signos constroem seus saberes, trazem a possibilidade de pensarmos em desenhos de formação inicial e continuada para essas profissionais.

Para este texto, optamos por analisar parte dos dados referentes à formação inicial e continuada e condições de trabalho das profissionais das creches envolvidas na primeira etapa da pesquisa. Espera-se que os resultados desta investigação possam subsidiar as discussões sobre as especificidades da formação da professora que atua com bebês e crianças de 0 a 3 anos e impactar o desenho das políticas públicas de formação dessa profissional que atuará com esses sujeitos de pouca idade no contexto da creche.

\footnotetext{
1 Optamos por utilizar, no decorrer do texto, o gênero feminino, vez que, como ocorre na pesquisa em questão, no contexto da creche, a maioria de profissionais se constitui de mulheres.
}

\section{A Educação Infantil e os dilemas da formação de seus profissionais}

Discutir formação de professores é, ainda, um tema atual e complexo. É necessário nos interrogarmos sobre a natureza da formação de professores e de que modo essa formação deve acontecer. Para Tardif e Lessard (2005), o magistério não pode ser colocado como uma ocupação secundária. Ele constitui um setor nevrálgico nas sociedades contemporâneas, uma das chaves para entender as suas transformações. No que concerne à formação de professores, é necessária uma verdadeira revolução nas estruturas institucionais formativas e nos currículos de formação. As emendas já são muitas. A fragmentação formativa é clara. É preciso integrar essa formação em currículos articulados e voltados a esse objetivo precípuo.

A formação dos professores, no campo da Educação Infantil, em especial, para a faixa etária de 0 a 3 anos, é emblemática no Brasil. Enfrentamos um embate instigante na atualidade: refletir sobre o desenho dessa formação, que fuja do embrutecimento que promove alienação e automatização. Assim, que saberes são eleitos ou devem ser privilegiados na formação inicial? Quais são aqueles que possibilitam a construção de práticas que priorizam bebês e crianças pequenas e suas experiências? Isso também deve ser levado em consideração nas discussões sobre reforma curricular dos cursos que formam o professor na própria Universidade.

Dizer que há atributos, habilidades e competências específicas para trabalhar com crianças pequenas é uma tendência recente, se considerarmos que, até bem pouco tempo, boa vontade, carinho, paciência, amor eram as características popularmente conhecidas e desejadas. Questões dessa natureza incidem no modo de pensar a formação dos professores. Entendemos que essa formação deva contemplar não somente os saberes produzidos e sistematizados pela academia, mas também o permanente diálogo com outros espaços, dentre eles, o contexto das práticas no campo da Educação Infantil.

Esses elementos são determinados historicamente e incidem sobremaneira no cotidiano das instituições destinadas a trabalhar com crianças e bebês de 0 a 3 anos. Isso não é diferente no caso do município de Juiz de Fora/MG. Por isso, investigar como ocorre a 
formação inicial de professoras que atuam com bebês e crianças pequenas é importante porque, a partir dessa discussão, será possível repensarmos a organização curricular dos cursos de formação e sugerir temas para as políticas de formação inicial e continuada no âmbito local e nacional.

Ao considerarmos as discussões sobre a educação na atualidade, observamos que a educação destinada às crianças de 0 a 5 anos vem sendo reconhecida em diversas esferas da sociedade. Nessa trajetória de reconhecimento da Educação Infantil como primeira etapa da Educação Básica, muitas vozes, oriundas de diversos atores da sociedade, se pronunciaram na luta pelo direito da criança à educação.

Essas vozes, que assumiram a luta em prol das crianças e do seu direito à educação, pressionaram legisladores e construíram, junto com os governos, uma política educacional pautada nos princípios democráticos. De acordo com Corsino e Nunes (2010, p. 14),

$$
\begin{aligned}
& \text { sem o movimento social } \\
& \text { organizado, não teria sido } \\
& \text { possível vislumbrar as } \\
& \text { conquistas já hoje } \\
& \text { alcançadas, na cobertura } \\
& \text { do atendimento, na } \\
& \text { elaboração de um } \\
& \text { currículo para a infância } \\
& \text { com indicadores de } \\
& \text { qualidade, no } \\
& \text { financiamento, nos canais } \\
& \text { de participação e controle } \\
& \text { social etc. Talvez esta } \\
& \text { tenha sido uma das } \\
& \text { maiores lições vividas pelo } \\
& \text { Estado brasileiro, que vem } \\
& \text { dialogando e enfrentando } \\
& \text { os desafios postos pela } \\
& \text { sociedade em prol da } \\
& \text { opção adotada na } \\
& \text { formulação da política } \\
& \text { nacional de educação } \\
& \text { infantil. }
\end{aligned}
$$

Apesar dessa trajetória de luta pelo direito à Educação Infantil, é preciso reconhecer a presença de contradições e avanços que ainda precisam ser conquistados. $O$ debate em torno de temas como formação e condições de trabalho dos docentes, currículo e propostas pedagógicas, parâmetros de infraestrutura, qualidade e avaliação, financiamento são emblemáticos e precisam ser enfrentados. Em que pese o fato de as crianças pequenas terem ganhado visibilidade no contexto das políticas públicas, é preciso clareza em relação à educação que queremos para elas.

Hoje, ao se discutirem as políticas sob a ótica da qualidade e identidade da Educação Infantil, evidencia-se que, por suas especificidades, o trabalho com essa etapa da Educação Básica prescinde de uma ampla discussão sobre formação dos professores. Campos (2011, p. 220) ressalta, por exemplo, que a) essa etapa educativa é orientada por uma especificidade, decorrente da própria natureza dos processos educativos desenvolvidos com e para as crianças pequenas; $b$ ) educar e cuidar, tomados de modo indissociável, constituem-se como núcleos estruturantes tanto das propostas curriculares quanto da prática docente em creches e pré-escolas; e c) o trabalho pedagógico desenvolve-se em relação de complementaridade com as práticas educativas e de socialização desenvolvidas pelas famílias.

No campo das políticas públicas, o atual Plano Nacional de Educação (BRASIL, 2014) apresenta desafios para a Educação Infantil e para a formação de seus profissionais. A meta 1 do referido plano propôs

universalizar, até 2016, a Educação Infantil na préescola para as crianças de 4 (quatro) a 5 (cinco) anos de idade e ampliar a oferta de Educação Infantil em creches de forma a atender, no mínimo, 50\% (cinquenta por cento) das crianças de até 3 (três) anos até o final da vigência deste PNE.

Para essa meta, o Plano Nacional de Educação (PNE) estabeleceu 17 estratégias de ação. As estratégias 1.8 e 1.9 referem-se especificamente à formação dos profissionais e orientam: 
1.8 promover a formação inicial e continuada dos (as) profissionais da educação infantil, garantindo, progressivamente, o atendimento por profissionais com formação superior; 1.9 estimular a articulação entre pós-graduação, núcleos de pesquisa e cursos de formação para profissionais da educação, de modo a garantir a elaboração de currículos e propostas pedagógicas que incorporem os avanços de pesquisas ligadas ao processo de ensino-aprendizagem e às teorias educacionais no atendimento da população de 0 (zero) a 5 (cinco) anos (BRASIL, 2014).

Sendo assim, o PNE anuncia desafios e proposições para a Educação Infantil e para a formação das profissionais que atuam nessa etapa. Podemos destacar um avanço a busca pela articulação entre os níveis de ensino, com os núcleos de pesquisas e os contextos das práticas das professoras. Assim, ao refletirmos sobre os caminhos para a formação das professoras, consideramos fundamental a implementação e a concretização de políticas e propostas articuladas para essa etapa, buscando uma real integração entre formação inicial, formação continuada, pesquisa e instituições de Educação Infantil. Corroboramos com o pensamento de Dourado (2013), quando aponta que um grande desafio no campo educacional é repensar a formação, estabelecendo políticas mais orgânicas, buscando articular a formação inicial e a continuada.

Se por um lado a formação inicial é desejada como pré-requisito para o ingresso na carreira, por outro a formação continuada passa a ser vista como estratégia para a melhoria permanente da qualidade da educação, tendo como principal finalidade, a reflexão sobre a prática educacional e a busca do aperfeiçoamento técnico, ético e político, que não se restringe a esta prática (DOURADO, p. 377-378).

Dessa forma, é preciso pensar em processos de formação contextualizados, abertos às reais demandas das instituições, visando à consolidação de ações significativas para aquelas que atuam nas diferentes esferas da educação no Brasil. Isso pressupõe oferecer possibilidade de formação de qualidade, tanto inicial como continuada, tendo como pressuposto a reflexão crítica sobre suas próprias vivências e práticas cotidianas, visando romper com a dicotomia teoria-prática.

São esses os desafios que movem o grupo de pesquisa LICEDH/UFJF que busca, através da pesquisa, almejar caminhos outros para a formação de professoras de crianças pequenas. A seguir apresentaremos parte dos dados da pesquisa que foi desenvolvida no interior do GP LICEDH.

\section{Os caminhos da pesquisa}

A pesquisa intitulada "Sentidos e significados sobre a formação do(a) professor(a) das creches conveniadas do município de Juiz de Fora/MG" aconteceu durante o ano de 2016 e teve como objetivo construir o perfil da professora que atua em creches conveniadas do município, buscando compreender quais são os saberes/fazeres docentes necessários para atuação com bebês e crianças na faixa etária de 0 a 3 anos de idade. A abordagem de pesquisa adotada utilizou a perspectiva quantitativa e qualitativa. Para alcançar o primeiro objetivo, qual seja, construir o perfil do(a) professora que atua em creches conveniadas do município de Juiz de Fora/MG, foi necessário utilizar a abordagem quantitativa, que nos permitiu construir um questionário de escala de resposta psicométrica tipo Likert. Em uma segunda etapa, utilizamos uma abordagem qualitativa de pesquisa, que permitiu compreender os sentidos subjetivos e significados que foram construídos entre as participantes da pesquisa, voltando-se para o encontro e o confronto de indicadores, que foram se desvelando e integrando o momento interpretativo.

Neste texto nos deteremos a apresentar os dados produzidos na primeira etapa da pesquisa, em que foi construído um questionário, que versou sobre o perfil das professoras, 
particularmente em relação à sua formação (inicial e continuada), condições de trabalho e às práticas pedagógicas empreendidas. As questões foram elaboradas tendo como base orientações legais que regem a formação de professores da Educação Básica na atualidade, assim como as diretrizes e as concepções no campo da Educação Infantil. Os documentos produzidos pelo Ministério da Educação (MEC), intitulados "Diretrizes Curriculares Nacionais para a Educação Infantil" (BRASIL, 2009a), e "Indicadores da Qualidade na Educação Infantil" (BRASIL, 2009b), serviram como parâmetro para a construção das questões relacionadas ao planejamento institucional, multiplicidade de experiências e linguagens, interações, formação e condições de trabalho dos professores e demais profissionais.

O questionário foi composto por 67 questões, sendo que a maioria das variáveis foi construída com base na escala Likert. A proposta foi apresentada em reunião específica às coordenadoras de 26 creches conveniadas do município de Juiz de Fora/MG, ocasião em que foram explicitados os motivos e as implicações da pesquisa. Os questionários foram encaminhados às creches e respondidos pelas professoras que atuam nessas instituições conveniadas. Em um universo de 26 creches conveniadas com a prefeitura de Juiz de Fora/MG, com um total de 277 professoras de crianças de 0 a 3 anos, foram respondidos 248 questionários, correspondendo a $89,5 \%$ do total, percentual mais do que suficiente para atestar a representatividade do número de respondentes em relação ao total da rede. As frequências das variáveis e os cruzamentos entre elas foram produzidos através do uso do "software" de análise de dados Statistical Package for the Social Sciences (SPSS).

Todas as informações dos questionários foram recolhidas e registradas em um documento de Excel, formando uma base de dados prévia. Em seguida, essa base foi importada para o SSPS para ser tratada, sendo as variáveis recodificadas e renomeadas, constituindo uma nova base de dados. Todas as tabelas de frequência foram montadas através da ferramenta de análise do próprio SPSS, apontando o número de casos e o percentual válido. Os cruzamentos, por sua vez, foram realizados através da ferramenta de análise Crosstabs, que organiza, em colunas e linhas, diferentes informações, permitindo observar como dados variam em função de determinados grupos.]
Conhecendo as profissionais que atuam nas creches conveniadas do município de Juiz de Fora/MG

Juiz de Fora/MG possui uma rede de creches conveniadas com a prefeitura municipal para o atendimento educacional das crianças e bebês de 0 a 3 anos. Por não possuir uma rede direta de gestão dessas creches, a opção do município é a realização de convênios com instituições comunitárias e filantrópicas sem fins lucrativos, que passam a ser prestadoras desse serviço para o município. Segundo documento publicado pelo Ministério da Educação intitulado "Orientações sobre Convênios entre Secretarias Municipais de Educação e Instituições Comunitárias, Confessionais ou Filantrópicas Sem Fins Lucrativos para a oferta da Educação Infantil" (BRASIL, 2009c), à Secretaria de Educação cabe orientar, fiscalizar e avaliar, periodicamente, o planejamento e a utilização dos recursos repassados à instituição conveniada, observando o plano de aplicação; garantir assessoramento pedagógico e administrativo; acompanhar e supervisionar as ações pedagógicas, de saúde e de alimentação.

Em Juiz de Fora/MG, observamos uma contradição em relação à organização da Educação Infantil. Enquanto a pré-escola tem atendimento praticamente universalizado no município, inclusive com professores concursados e com carreira própria, de acordo com o que preconiza a legislação, no segmento de creche, de forma contrastante, todo o atendimento é realizado através de convênios com entidades privadas sem fins lucrativos. O município também possui uma extensa demanda de bebês e crianças que não conseguem vagas nas creches. As profissionais que atuam nessas instituições, apesar de terem a formação mínima exigida pela legislação, não possuem carreira própria e são contratadas como educadoras. No momento da realização da pesquisa, existiam 28 instituições ${ }^{2}$ conveniadas com a prefeitura para o atendimento educacional dos bebês e crianças nas creches.

Estudos realizados por Rosemberg (2001, 2002) nos possibilitam compreender que o modelo para a oferta do atendimento de creche adotado no município de Juiz de Fora/MG tem suas raízes na história das políticas de Educação Infantil no Brasil que, assim como em outros

\footnotetext{
${ }^{2}$ No momento da aplicação do questionário eram 26 creches. Duas foram inauguradas em momento posterior e, portanto, não participaram da primeira etapa da pesquisa.
} 
países em desenvolvimento, sofreu forte influência de modelos considerados "não formais", defendidos por organismos multilaterais. Tais modelos, pautados no que a autora denominou de "educação para subalternidade", têm como pano de fundo a precariedade, o baixo investimento público, modelos incompletos ou emergenciais de atendimento, ancorados em uma flexibilização do sistema. Para Rosemberg (2007), são modelos que não dão conta das dimensões consensuadas sobre a especificidade do trabalho na Educação Infantil, qual seja, educar/cuidar com equidade e qualidade.

\section{Perfil geral do corpo docente}

A seguir, são descritas as principais características do corpo docente que respondeu aos questionários da pesquisa. Em geral, é possível observar mais de duzentas e trinta respondentes para cada variável do questionário, com variações para baixo e para cima em relação a esse número. As tabelas são apresentadas, com frequência e percentual, e acompanhadas de uma descrição acerca dos dados. Ao final da presente seção, há um breve resumo do perfil das professoras que trabalham no segmento de Educação Infantil em Juiz de Fora/MG, tendo em vista as creches conveniadas.

Tabela 1. Sexo dos respondentes

\begin{tabular}{c|c|c}
\hline Sexo & Frequência & Percentual \\
\hline Masculino & 2 & 0,84 \\
\hline Feminino & 235 & 99,16 \\
\hline Total & 237 & 100
\end{tabular}

Fonte: Tabulação própria a partir dos dados produzidos na pesquisa no ano de 2016

Podemos afirmar que, nas creches conveniadas de Juiz de Fora/MG, o corpo docente é principalmente composto por mulheres. Como podemos observar na Tabela 1, a maioria dos respondentes é formada por mulheres, mais de $99 \%$ do total.

Tabela 2. Tempo como professora na Educação Infantil

\begin{tabular}{c|c|c}
\hline \multicolumn{3}{c}{ Há quanto tempo você trabalha como professora na } \\
Educação Infantil? \\
\hline Grupos & Frequência & Percentual \\
\hline Menos de um ano & 21 & 8,54 \\
\hline Um ano & 8 & 3,25 \\
\hline Entre 1 e 3 anos & 56 & 22,76 \\
\hline Entre 3 e 5 anos & 43 & 17,48 \\
\hline Entre 5 e 10 anos & 25 & 10,16 \\
\hline Mais de 10 anos & 93 & 37,80 \\
\hline Total & 246 & 100 \\
\hline
\end{tabular}

Fonte: Tabulação própria a partir dos dados produzidos na pesquisa no ano de 2016

A leitura da Tabela 2 mostra que o grupo com maior percentual $(37,8 \%)$ é aquele que já trabalha com a Educação Infantil há mais de dez anos. Ou seja, trata-se de professoras com considerável experiência no segmento. Outros
27,5\% estão entre três e dez anos trabalhando como professoras na etapa. Por fim, cerca de $33 \%$ do total de respondentes estão trabalhando há menos de três anos. 
Tabela 3. Tempo em que trabalha na creche atual

\begin{tabular}{c|c|c}
\hline \multicolumn{3}{c}{ Há quanto tempo trabalha como professora nesta } \\
creche?
\end{tabular}

Fonte: Tabulação própria a partir dos dados produzidos na pesquisa no ano de 2016

Os dados da Tabela 3 trazem informações sobre o tempo em que as respondentes trabalham, especificamente, na creche em que estavam atuando quando o questionário foi aplicado. É possível notar que o grupo com maior percentual de respondentes é aquele com menos de um ano de trabalho na creche $(28,5 \%)$. Em seguida, com $27,3 \%$, estão aquelas que trabalham entre 1 e 3 anos na mesma instituição.
Pouco mais de $13 \%$ do total disseram trabalhar há mais de 10 anos na mesma creche. Assim, cotejando essas informações com as apresentadas na Tabela 2, podemos dizer que, embora boa parte das respondentes já trabalhe com Educação Infantil há mais de 10 anos, muitas delas não se encontram há tanto tempo na mesma instituição. É o que mostra a Tabela 4, a seguir. 
Tabela 4. Tempo como docente e tempo como docente na creche atual

\begin{tabular}{|c|c|c|c|c|c|c|c|c|}
\hline \multirow{9}{*}{$\begin{array}{l}\text { Há quanto } \\
\text { tempo } \\
\text { você } \\
\text { trabalha } \\
\text { como } \\
\text { professora } \\
\text { na } \\
\text { Educação } \\
\text { Infantil? }\end{array}$} & \multicolumn{8}{|c|}{ Há quanto tempo trabalha como professora nesta creche? } \\
\hline & Grupos & $\begin{array}{c}\text { Menos de } \\
\text { um ano }\end{array}$ & $\begin{array}{l}\text { Um } \\
\text { ano }\end{array}$ & $\begin{array}{c}\text { Entre } 1 \mathrm{e} \\
3 \text { anos }\end{array}$ & $\begin{array}{c}\text { Entre } 3 \text { e } \\
5 \text { anos }\end{array}$ & $\begin{array}{c}\text { Entre } 5 \text { e } \\
10 \text { anos }\end{array}$ & $\begin{array}{l}\text { Mais de } \\
10 \text { anos }\end{array}$ & Total \\
\hline & $\begin{array}{c}\text { Menos de um } \\
\text { ano }\end{array}$ & 20 & 0 & 0 & 0 & 0 & 0 & 20 \\
\hline & Um ano & 5 & 1 & 0 & 0 & 0 & 0 & 6 \\
\hline & $\begin{array}{c}\text { Entre } 1 \text { e } 3 \\
\text { anos }\end{array}$ & 18 & 4 & 30 & 1 & 0 & 0 & 53 \\
\hline & $\begin{array}{l}\text { Entre } 3 \text { e } 5 \\
\text { anos }\end{array}$ & 13 & 4 & 13 & 13 & 0 & 0 & 43 \\
\hline & $\begin{array}{c}\text { Entre } 5 \text { e } 10 \\
\text { anos }\end{array}$ & 6 & 2 & 7 & 7 & 3 & 0 & 25 \\
\hline & $\begin{array}{l}\text { Mais de } 10 \\
\text { anos }\end{array}$ & 6 & 2 & 14 & 12 & 25 & 30 & 89 \\
\hline & Total & 68 & 13 & 64 & 33 & 28 & 30 & 236 \\
\hline
\end{tabular}

Fonte:Tabulação própria a partir dos dados produzidos na pesquisa no ano de 2016

Sobre a formação em relação ao Ensino Médio, os dados revelam que a maioria das professoras $(68,4 \%)$ cursou o Magistério no Ensino Médio, (64,5\%), em instituições públicas. Observando-se os dados relativos à graduação das respondentes, percebe-se que 37,39\% não possuem curso de graduação, ao passo que $15,2 \%$ estão fazendo graduação e $47,3 \%$ já a concluíram. Mais da metade, portanto, não tem curso de graduação concluído. Para as que estão fazendo ou já fizeram graduação, a maioria cursou ou cursa Pedagogia (52,2\%), enquanto que $5 \%$ marcaram a opção Normal Superior. Em relação à instituição em que cursou ou cursa a graduação, a maioria o fez em instituição privada, representando $55 \%$ do total, ao passo que apenas $8,3 \%$ cursaram em instituição pública (o restante não cursou graduação). Entre aquelas que já terminaram a graduação, há uma distribuição equitativa pelos grupos de tempo em que o curso foi concluído. O maior percentual é representado pelo grupo que concluiu a graduação há, no mínimo, dois e, no máximo, cinco anos. Ou seja, trata-se de um público que não se graduou há muito tempo.

No que tange à pós-graduação, a maioria não fez ou faz especialização $(84,1 \%)$. Entre as que fizeram, a maioria fez o curso em instituição privada. Além disso, a imensa maioria das respondentes (99\%) não fez ou faz pós-graduação stricto sensu na área de Educação.

Quando questionadas sobre a frequência com que participam de cursos de formação continuada, as respondentes, em sua maioria, disseram que nunca ou raramente participam desses cursos ( $14,4 \%$ e $40,3 \%$, respectivamente). As que disseram que sempre participam dos cursos de formação respondem por $18,9 \%$ do total, enquanto é de 26,3 o percentual daquelas que dizem participar frequentemente da formação continuada.

Em termos de um perfil geral, portanto, podemos dizer que o corpo docente das creches conveniadas de Juiz de Fora é formado, em sua maioria, por mulheres, que trabalham há mais de três anos nesse segmento (com destaque para o percentual daquelas que trabalham há mais de dez anos, 37\%), mas com atuação inferior a três anos na creche na qual estão hoje (com destaque para o percentual daquelas que não completaram um ano ainda na instituição atual, 28,5\%). Assim, é possível dizer que é um grupo de profissionais que, embora possua razoável experiência na Educação Infantil, não se encontra trabalhando na mesma creche há muito tempo. A maioria cursou o Magistério, nível Médio, em instituições públicas. No que tange à graduação, mais de $50 \%$ ainda não a possuem (dos quais, 15\% estão cursando) e aquelas que já se graduaram, em sua maioria, fizeram-no em instituições privadas, no curso de Pedagogia, e com finalização no período de dois a dez anos atrás (destaque para quem se formou entre dois e cinco anos). Isso quer dizer que parcela significativa das professoras se graduou há pouco tempo, tendo em vista que muitas já atuam no segmento há mais de dez anos. A maioria não fez ou faz especialização e há apenas dois casos com pós-graduação stricto 
sensu. A maioria participa raramente ou não participa de cursos de formação continuada.

Os dados apresentados acima demonstram fragilidades em relação à formação inicial e continuada das professoras das creches. Sobre essa questão, é preciso problematizar que a docência na Educação Infantil, especialmente na creche, configura-se como um campo em construção, marcado por características particulares, de indissociabilidade entre o cuidar e o educar e o compartilhamento dessas funções com a família (BRASIL, 2009a). Para Barbosa (2010), a docência na Educação Infantil exige da professora competência teórica, metodológica e relacional.

Nessa perspectiva, as professoras das creches e pré-escolas não podem ser consideradas docentes que ministram "conteúdos". Trata-se de uma formação específica, que requer discussões acerca das concepções contemporâneas de criança, infância e Educação Infantil. Tais especificidades nos levam a enfatizar a necessidade da formação continuada para o fortalecimento da identidade profissional das professoras das creches, assim como no estabelecimento de relações entre teoria e práticas na Educação Infantil.

Quando perguntadas sobre a renda bruta, mais de $80 \%$ das respondentes afirmaram que a renda ficava entre $\mathrm{R} \$ 678,01$ a $\mathrm{R} \$$ $1.356,00^{3}$. Isso quer dizer que essas profissionais não recebiam sequer o valor do Piso Nacional dos Professores, cujo vencimento, na época ${ }^{4}$, estava estipulado em $\mathrm{R} \$ \mathbf{2 . 1 3 5 , 6 4}$ e deveria ser pago para os professores da Educação Básica com jornada de até quarenta horas semanais. A relação entre a baixa remuneração e a falta de identidade com o magistério pode ser inferida nos dados produzidos a partir de questões que buscaram revelar a satisfação profissional e a identidade com a profissão. Os dados demonstram que mais de $50 \%$ das respondentes não sentem que são tratadas como professoras.

Campos (2011) nos ajuda na compreensão acerca do que seja uma identidade docente na Educação Infantil, que para a autora passa pela valorização e formação dessas profissionais em um campo de concepções que é

\footnotetext{
${ }^{3}$ As profissionais que atuam nas creches conveniadas do município de Juiz de Fora/MG trabalham quarenta horas semanais, não são contratadas como professoras, mas como educadoras, recebendo menos do que estipula o Piso Nacional do Magistério para uma jornada de até quarenta horas semanais.

${ }^{4}$ Ano de 2016.
}

atravessado por discussões acerca das infâncias, das formas de planejamento, da avaliação e documentação pedagógica, do cuidar e educar como práticas indissociáveis e das interações e brincadeiras como eixos fundantes da proposta pedagógica.

\section{Um passo além do perfil descritivo: algumas análises a partir da produção dos dados da pesquisa}

Além de descrever o perfil do corpo docente com base nas respostas dadas a cada variável do questionário, o cruzamento entre as diferentes informações produzidas permitiu escamotear melhor as relações entre cada uma das características investigadas pelo instrumento de pesquisa. Isso possibilitou a construção de um panorama mais amplo acerca de quem é a professora da Educação Infantil das creches conveniadas do município de Juiz de Fora/MG.

Quando realizamos um cruzamento entre a frequência em cursos de formação continuada e o tempo de trabalho na Educação Infantil, o que pode ser observado é que, proporcionalmente, a frequência em cursos de formação continuada é maior entre aquelas que já trabalham entre 3 e 5 anos com o segmento (o número de respondentes que optaram pela alternativa "sempre" é maior do que o número daquelas que responderam "raramente", por exemplo). Entre as professoras que já trabalham há mais de 10 anos no segmento, o maior número de respondentes optou pela alternativa "raramente", para definir a frequência com que participa de cursos de formação continuada.

A relação entre a formação no Ensino Médio e o tempo de trabalho na Educação Infantil também foi analisada. O que se pode perceber é que o Magistério foi cursado, como regra, por aquelas professoras que já possuem mais de 10 anos de experiência na Educação Infantil. Isso leva a pensar que aquelas profissionais que concluem a graduação não permanecem muito tempo na creche, já que não há um plano de carreira e salários que possam atraí-las a permanecer nesse segmento.

Ainda em relação à formação, podemos observar que a grande maioria entre aquelas que não possuem curso de graduação fez Magistério. Dos 149 casos com Magistério, apenas 45 deles concluíram o curso de graduação. As professoras que fizeram o Ensino Médio sem o Magistério, em regra, possuíam curso de graduação 
concluído (58 das 72). Isso sugere que aquelas que fizeram Magistério podem, uma vez no mercado de trabalho, não serem incentivadas a prosseguir seus estudos por não possuírem um plano de carreira que invista na sua formação.

Trabalhos realizados por Peroni (2013) e Nunes (2015) demonstram que no Brasil, historicamente, as condições de trabalho, de formação continuada e de contratação de profissionais nas instituições de Educação Infantil conveniadas são inferiores e mais precárias do que aquelas geridas pelo poder público diretamente. Isso acarreta uma contradição, pois, ao investir dinheiro público para manter as instituições privadas em detrimento das instituições públicas, o município se afasta da possibilidade de qualificar, investir e ampliar a sua rede direta. Essa realidade pode ser constatada no município de Juiz de Fora/MG.

Campos e Barbosa (2017) reforçam essa discussão ao apontar que a política de conveniamento gera uma situação paradoxal, uma vez que os recursos públicos ficam cada vez mais comprometidos para a manutenção dos convênios, o que ocasiona menores investimentos na manutenção, formação de professores ou na ampliação dos próprios sistemas de ensino do município, fato que compromete o trabalho desenvolvido.

Os dados revelam uma alta rotatividade de professoras nas creches, fato que pode ocasionar uma falta de vínculo institucional. Apesar de os dados produzidos apontarem que a maioria das professoras tem a formação mínima exigida (Magistério nível médio, Pedagogia ou curso Normal Superior), para atuarem na creche, uma questão relevante diz respeito ao fato de que, dentre o universo das que fizeram graduação, 84\% não fez pós-graduação. Isso pode ter relação com a falta de incentivo, já que essas profissionais não possuem um plano de carreira que invista em sua formação, diferentemente dos demais profissionais do magistério público municipal de Juiz de Fora/MG. É também considerável o número de professoras que disseram que nunca $(14,4 \%)$ ou raramente $(40,3 \%)$ participam de curso de formação continuada. Esse fato tem suas raízes na dura jornada de trabalho (40h semanais) que essas profissionais enfrentam, demonstrando que a Lei do Piso ${ }^{5}$ (BRASIL, 2008), que estabelece que $1 / 3$

\footnotetext{
${ }^{5}$ A Lei no $11.738 / 2008$ (BRASIL, 2008) regulamenta o piso salarial profissional nacional para os profissionais do magistério público da Educação Básica. No segundo parágrafo do artigo 20 da respectiva
}

da carga horária do professor seja destinada às atividades extraclasse, não é respeitada. Tal fato também leva a problematizar a falta de investimento do poder público municipal no que tange à formação continuada dessas profissionais, tarefa que é de sua responsabilidade.

Pesquisas como as de Kramer e Nunes (2015), demonstram que, se houve avanços em relação à expansão de matrículas em creches no Brasil, ainda é preciso garantir questões fundamentais tais como abertura de concursos específicos para professor de Educação Infantil, inclusão de carga horária específica para planejamento e formação em serviço e plano de cargos e salários compatível com a função docente. A pesquisa apresentada pelas autoras traz uma realidade que é constatada em muitos municípios, como também em Juiz de Fora/MG, o que nos faz questionar os entraves que ainda persistem, mesmo após a creche estar integrada aos respectivos sistemas educacionais de nosso país.

\section{Apontamentos finais}

Sabemos que a origem das contradições entre a creche e a pré-escola possui raízes históricas. Campos (2010) assevera que, apesar das mudanças nos aspectos legais, a cisão entre a creche e a pré-escola ainda não foi superada. Exemplo disso é a constatação da transferência tardia das creches dos órgãos de assistência social para a educação em muitos municípios. Outra realidade preocupante é a ausência de uma carreira para as profissionais que atuam nas creches, a exclusão dessas profissionais em programas de formação continuada, ausência da discussão sobre as especificidades do trabalho com bebês e crianças pequenas nos cursos de formação inicial, infraestrutura adaptada para o funcionamento das instituições. Além disso, é preciso ressaltar o fato de que, em muitos municípios, perpetua o sistema de convênio com

\footnotetext{
Lei, por profissionais do magistério público da Educação Básica entendem-se aqueles que desempenham as atividades de docência ou as de suporte pedagógico à docência, isto é, direção ou administração, planejamento, inspeção, supervisão, orientação e coordenação educacionais, exercidas no âmbito das unidades escolares de Educação Básica, em suas diversas etapas e modalidades, com a formação mínima determinada pela legislação federal de diretrizes e bases da educação nacional. No parágrafo 40 estabelece que, na composição da jornada de trabalho, observar-seá o limite máximo de $2 / 3$ (dois terços) da carga horária para o desempenho das atividades de interação com os(as) educandos(as).
} 
entidades privadas sem fins lucrativos para realizar o atendimento educacional da faixa etária de 0 a 3 anos.

Os dados produzidos a partir da pesquisa revelam questões que se inter-relacionam e que são os pontos frágeis que trazem entraves à identidade da Educação Infantil no município de Juiz de Fora/MG: aspectos relacionados à gestão das creches, condições de trabalho das profissionais e sua formação inicial e continuada. Apesar de termos uma gama de disposições legais que caminham na garantia às profissionais que atuam nas creches melhores condições de trabalho e de carreira, o que se revela é o fato de que, em Juiz de Fora/MG, assim como em muitos municípios, tenta-se burlar a legislação contratando auxiliares, educadores, recreadores, desprestigiando e não reconhecendo a função docente. Ao se criarem essas categorias paralelas, destitui-se do espaço educativo da creche a professora, o que enfraquece a profissionalização docente, desvirtuando o ideal da identidade da Educação Infantil.

Sobre a formação, entendemos que ela deva ser concebida como algo que pode se dar antes, durante e depois do processo formal, como espaços de reflexão sobre o próprio trabalho, em seu próprio contexto. Ao pensarmos dessa maneira a formação, seja ela inicial ou continuada, deixará de ser entendida/percebida somente como uma questão de posse ou de construção de conhecimentos teóricos destinados à prática, mas se constituirá em um processo de intervenção na prática, alicerçado nos conhecimentos produzidos pelas áreas científicas disciplinares e nos saberes que os(as) educadores(as) constroem no contexto de trabalho no qual estão imersos (FERREIRA, 2007).

No caso do município de Juiz de Fora/MG, a pesquisa revelou que grande parte dos profissionais que atua nas creches investigadas não participa de cursos de formação continuada com a frequência necessária, demonstrando que o poder público não vem atuando conforme preconiza as orientações legais. Isso é demonstrado através da desconsideração do município em implementar ações no sentido de estabelecer o previsto na meta 1 do atual Plano Nacional de Educação (BRASIL, 2014), especificamente em relação às estratégias 1.8 e 1.9 , conforme apresentado no início desse artigo. Sendo assim, podemos dizer que há uma fragmentação no processo formativo dessas profissionais. Nessa trajetória, é preciso reconhecer que a dura jornada de trabalho de 40 horas semanais não possibilita a essas profissionais dedicarem um tempo à sua formação continuada.

É preciso enfatizar que nesse processo muitos fatores contribuem para que os professores da Educação Básica, e os da Educação Infantil em particular, tenham uma formação inicial precária e não participem de formações continuadas. Autores(as) importantes na área da pesquisa educacional e da formação de professores apontam ser este um campo complexo que envolve dilemas estruturais que atravessam historicamente a Educação no Brasil. Tais entraves envolvem a fragmentação, dispersão e descontinuidade das iniciativas das políticas educacionais; financiamento da Educação Básica; separação entre as instituições formativas e as instituições escolares; paradoxo pedagógico revelado na contraposição entre teoria e prática; definição de princípios e diretrizes sobre o que constitui a formação inicial e continuada; lócus e concepções da instituição formadora; vinculação com processos culturais e identitários; condição de trabalho docente, entre outros (DOURADO, 2013; GATTI; BARRETO; ANDRÉ, 2011; SAVIANI, 2014).

Sabemos que, com relação à carreira dos professores que atuam nas creches, a LDB no 9394/96 equipara a carreira do professor da Educação Infantil ao professor dos anos iniciais do Ensino Fundamental, tendo categoria profissional definida, sindicalizada e que tem seu espaço legítimo de reivindicação. A Lei no 11.738/2008 (BRASIL, 2008) regulamentou o piso salarial profissional nacional para os profissionais do magistério público da Educação Básica. Em relação à formação continuada, diversos documentos e orientações legais preconizam esse direito aos professores.

No entanto, a partir dos dados produzidos na pesquisa realizada, questões importantes acerca da falta de identidade das profissionais que trabalham nas creches com a docência são fatores preocupantes. A ausência de investimento dos gestores municipais na constituição de uma carreira específica, com salários dignos e com tempo destinado à formação para essas profissionais, são sérios problemas que precisam ser enfrentados no município.

A pesquisa apontou para a necessidade de articulação entre as políticas de formação inicial e continuada de professores, considerando 
fundamental que o poder público assuma a responsabilidade por essas instituições, investindo, principalmente, em uma carreira para as profissionais que atuam nas creches. Esse é um caminho imprescindível para avançar no campo em que esta pesquisa possibilitou conhecer.

\section{REFERÊNCIAS}

BRASIL. Lei no 11.738/2008. Regulamenta a alínea "e" do inciso III do caput do art. 60 do Ato das Disposições Constitucionais Transitórias, para instituir o piso salarial profissional nacional para os profissionais do magistério público da educação básica. Presidência da República, 16 de julho de 2008. Brasília, 2008

BRASIL. Conselho Nacional de educação/ Câmara de Educação Básica. Resolução no 05, de 17 de dezembro de 2009. Fixa as Diretrizes Curriculares Nacionais para a Educação Infantil. Brasília, 2009a.

BRASIL. Ministério da Educação. Secretaria de Educação Básica. Indicadores da qualidade na Educação Infantil. Brasília: MEC/SEB, 2009b.

BRASIL. Ministério da Educação. Secretaria de Educação Básica (SEB). Orientações sobre convênios entre secretarias municipais de educação e instituições comunitárias, confessionais e filantrópicas sem fins lucrativos para a oferta da educação infantil. Brasília, 2009c.

BRASIL. Presidência da República. Lei no 13.005/2014. Aprova o Plano Nacional de Educação - PNE e dá outras providências. Brasília, 2014.

BARBOSA, Maria Carmem. Especificidades da ação pedagógica com os bebês. In: SEMINÁRIO NACIONAL CURRÍCULO EM MOVIMENTO PERSPECTIVAS ATUAIS, 1., Belo Horizonte, 2010. Anais... Belo Horizonte, 2010. Disponível em $<$ http://portal.mec.gov.br/docman/dezembro2010-pdf/7154-2-2-artigo-mec-acao-pedagogicabebes-m-carmem:file>. Acesso em: 22 fev. 2017.

CAMPOS, Maria Malta. A Educação Infantil como direito. In: Insumos para o debate 2: Emenda Constitucional no 59/2009 e a educação infantil: impactos e perspectivas. São Paulo: Campanha Nacional pelo Direito à Educação, 2010. p. 8-14.
CAMPOS, Roselane Fátima. Educação Infantil: políticas e identidade. Revista Retratos da Escola, Brasília, v. 5, n.9, p. 217-228, jul./dez. 2011.

CAMPOS, Rosânia; BARBOSA, Maria Carmen Silveira. A obrigatoriedade da matrícula na préescola em tempos de "terceira via". In: REUNIÃO NACIONAL DA ANPED, 38., São Luis. Anais... São Luis: ANPED, 2017.

CORSINO, Patrícia; NUNES, Maria Fernanda Rezende. Políticas públicas universalistas e residualistas: os desafios da educação infantil. In: REUNIÃO DA ANPED, 33., Caxambu. Anais... Caxambu: ANPEP, 2010.

DOURADO, Luiz Fernandes. A formação de professores e a base comum nacional: questões e proposições para o debate. Revista Brasileira de Política e Administração da Educação, v. 29, n.2, p. 367-388, mai/ago. 2013.

FERREIRA, Adir Luiz. Possibilidades e realismo crítico da Pesquisa e da Formação: a colaboração entre pesquisadores e professores. In: IBIAPINA, Ivana, M. L. de Melo; FERREIRA, Maria Salonilde; RIBEIRO, Márcia Maria Gurgel. Pesquisa em educação: múltiplos olhares. Brasília: Liber livro, 2007, v.1, p. 13-28.

GATTI, Bernardete Angelina; BARRETO, Elba Siqueira de Sá ; ANDRÉ, Marli Eliza D. Afonso. Políticas Docentes no Brasil: Um estado da arte. Brasília: UNESCO, 2011. 300 p.

NUNES, Maria Fernanda Rezende (Org). Proinfância $e$ as estratégias municipais de atendimento a crianças de 0 a 6 anos. Rio de Janeiro: Traço e Cultura, v. 1. 132p, 2015.

PERONI, Vera Maria Vidal. As relações entre o público e o privado nas políticas educacionais no contexto da terceira via. Currículo sem Fronteiras, v. 13 , n. 2 , p. 234-255, maio/ago, 2013.

ROSEMBERG, Fúlvia. Avaliação de programas, indicadores e projetos em educação infantil. Revista Brasileira de Educação, n. 16, p. 19-16, jan./fev/mar./abr. 2001.

ROSEMBERG, Fúlvia. Organizações Multilaterais, Estados e Políticas de Educação Infantil. Cadernos de Pesquisa, n. 115, p. 25-63, mar./2002. 
ROSEMBERG, Fúlvia. Educação Infantil pósFUNDEB: avanços e tensões. Texto apresentado no Seminário Educar na Infância: perspectivas histórico-sociais. Curitiba, 2007. Disponível em: http://www.diversidadeducainfantil.org.br/PDF/E duca\%C3\%A7\%C3\%A30\%20infantil\%20p\%C3\%B3 $\mathrm{s}-$

FUNDEB\%20avan\%C3\%A7os\%20e\%20tens\%C3\%B 5es\%20-\%20F\%C3\%BAlvia\%20Rosemberg.pdf.

Acesso em: 10 de agosto de 2016.

SAVIANI, Demerval. O lunar de Sepé: paixão, dilemas e perspectivas na educação. Campinas, SP: Autores Associados, 2014.

TARDIF, M.; LESSARD, C. O trabalho docente: elementos para uma teoria da docência como profissão de interações humanas. Petrópolis: Vozes, 2005.

Recebido para avaliação: 28/08/2018

Revisado em: 10/12/2018

Aceite Final: 13/12/2018 